\title{
MEASUREMENT OF LOWER LIMB ALIGNMENT USING LONG RADIOGRAPHS
}

\author{
JAMES G. WRIGHT， NICHOLAS TREBLE，ALVAN R. FEINSTEIN
}

\author{
From Yale University School of Medicine, Connecticut
}

\begin{abstract}
Long radiographs are used to measure lower limb axial alignment, to assess the progression of deformity, and to plan corrective surgery. The purpose of this study was to test the belief that jigs are necessary in order to control limb position for radiography.

Above-knee amputated limbs were fixed in different positions of rotation and of knee flexion and radiographed to study the effect on the apparent alignment of the limb. If the limb was rotated no more than $10^{\circ}$ from the neutral the effect on apparent axial alignment was minimal and radiographic measurement was reliable. This suggests that standardised positioning jigs are not needed in routine clinical practice.
\end{abstract}

Lower limb axial alignment is traditionally measured from radiographs with the patient standing; both legs are included on a single film.

We suspected that variable positioning of the limb by the radiographer would be a major source of inconsistent measurement of alignment. Such concern has led to the design of jigs that reduce the variability by standardising limb position (Wevers, Siu and Cooke 1982; Cooke, Siu and Fisher 1987). These jigs are not generally available and no study has documented their need. We therefore studied surgical specimens of aboveknee amputated limbs rather than patients, because of the radiation hazard.

\section{MATERIALS AND METHODS}

Apparatus. Radiographs of two high above-knee amputated limbs were taken on $35 \times 90 \mathrm{~cm}$ films in a graduated grid cassette. A transepicondylar Williams rod was placed across the distal femur of each limb, as shown in Figure 1. The female end of the rod was removed between radiographs, so that no portion of the rod was visible to

J. G. Wright, MD, FRCS C, Fellow in Clinical Epidemiology Robert Wood Johnson Clinical Scholars Program, Yale University School of Medicine, IE-61 SHM, New Haven, Connecticut 06510, USA.

N. Treble, MCh Orth, FRCS, Senior Registrar in Orthopaedics Croft End, Neston Road, Willaston, South Wirral, Merseyside L64 2T6, England.

A. R. Feinstein, MD, Professor of Medicine and Epidemiology Yale University School of Medicine, PO Box 3333, New Haven, Connecticut 06510, USA.

Correspondence should be sent to Dr J. G. Wright.

(C) 1991 British Editorial Society of Bone and Joint Surgery $0301-620 X / 91 / 5117 \$ 2.00$

J Bone Joint Surg [Br] 1991 ; 73-B:721-3. aid in positioning. A protractor placed over the rod and a plumb line were used to measure rotation in the transverse plane.

Rotation of the limbs. Five films were taken with the radiographer arranging the limbs using the patella as a guide to neutral rotation. After each radiograph had been taken, the female end of the Williams rod was reattached and the rotation measured. From the five rotational measurements, we first calculated a mean, called the 'position of neutral rotation'. We then rotated the limbs, using the protractor and plumb line, into four different positions $-10^{\circ}$ and $20^{\circ}$ each of external and internal rotation. Single AP radiographs were taken of the limb in each of these four positions.

Flexion of the knee. A Steinmann pin was placed obliquely

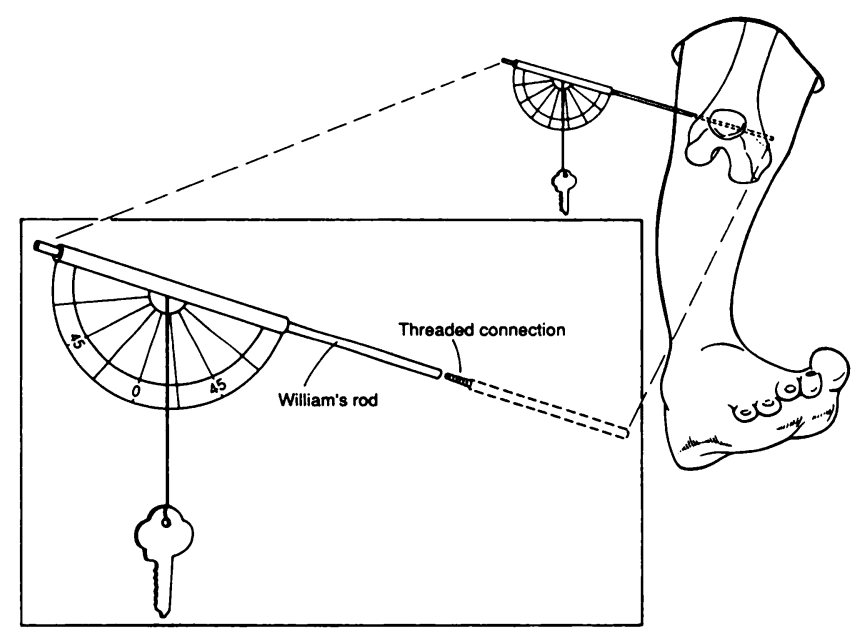

Fig. 1

Amputated limb with the Williams rod and apparatus used to measure limb rotation. 
across the joint, as shown in Figure 2, to fix the knee in $0^{\circ}, 20^{\circ}$ or $30^{\circ}$ of flexion. For each position of knee flexion we repeated five films in neutral rotation, calculated a new mean 'position of neutral rotation', and then obtained a single film in each of the four positions of rotation. On the second amputated limb the entire process was repeated except that the knee was fixed in only two positions of flexion $\left(0^{\circ}\right.$ and $\left.20^{\circ}\right)$, and only three films were taken in $20^{\circ}$ of flexion and neutral rotation.

The anatomical axis was measured on each of the 43 radiographs, by two observers (JGW and NT), both orthopaedic surgeons. They did not discuss measurement techniques, nor did they have combined practice sessions. The radiographs were measured by one observer once, and by the other observer on two occasions separated by one week, for a total of 129 observations. Each measurement was made 'blind' to prior measurements. Limb alignment was measured with the radiographs covered by clear acetate sheets that could be removed afterwards, leaving no permanent marks on the films.

Lower limb alignment was measured using the tibiofemoral 'anatomical' axis recommended by Moreland, Bassett and Hanker (1987). The angle was measured with $1^{\circ}$ precision, using a goniometer.

The intraclass correlation coefficient, an appropriate summary statistic for determining the reliability of measurement, or observer disagreement (Kramer and Feinstein 1981; Fleiss 1986) was used in this investigation and calculated from a 'two-way random effect' ANOVA model (Bartko 1966; Shrout and Fleiss 1979).

In the analysis of variance for the effect of rotation on limb alignment, the independent variables were the five rotation groups $\left(0^{\circ}, 10^{\circ}\right.$ and $20^{\circ}$ internal, $10^{\circ}$ and $20^{\circ}$ external) and the three knee flexion positions $\left(0^{\circ}, 20^{\circ}\right.$ and $30^{\circ}$ ). Using simple linear regression, rotation of the limb as the independent variable was contrasted with the limb alignment as the dependent variable using the SAS-PC computer program.

To assess the intra-observer disagreement, the intraclass correlation coefficient was calculated using the set of observations by one observer; the inter-observer disagreement used the first measurements of the two observers. The mean intra- and inter-observer differences were calculated from all 43 films.

\section{RESULTS}

Effect of rotation. As shown in Table I, the overall means for limb alignment showed little difference between the different rotation groups. The ANOVA $(p=0.6)$ and regression analysis (beta $=0.04, p=0.97$ ) confirmed that rotation did not have a significant effect on the apparent alignment with the limb rotated less than $10^{\circ}$. The radiographer positioned the limbs on average within $3.1^{\circ}$ of the 'position of neutral rotation' (SD $=2.7^{\circ}$ ).

As shown in Table II, the observers varied only slightly in their mean measurement of limb alignment.

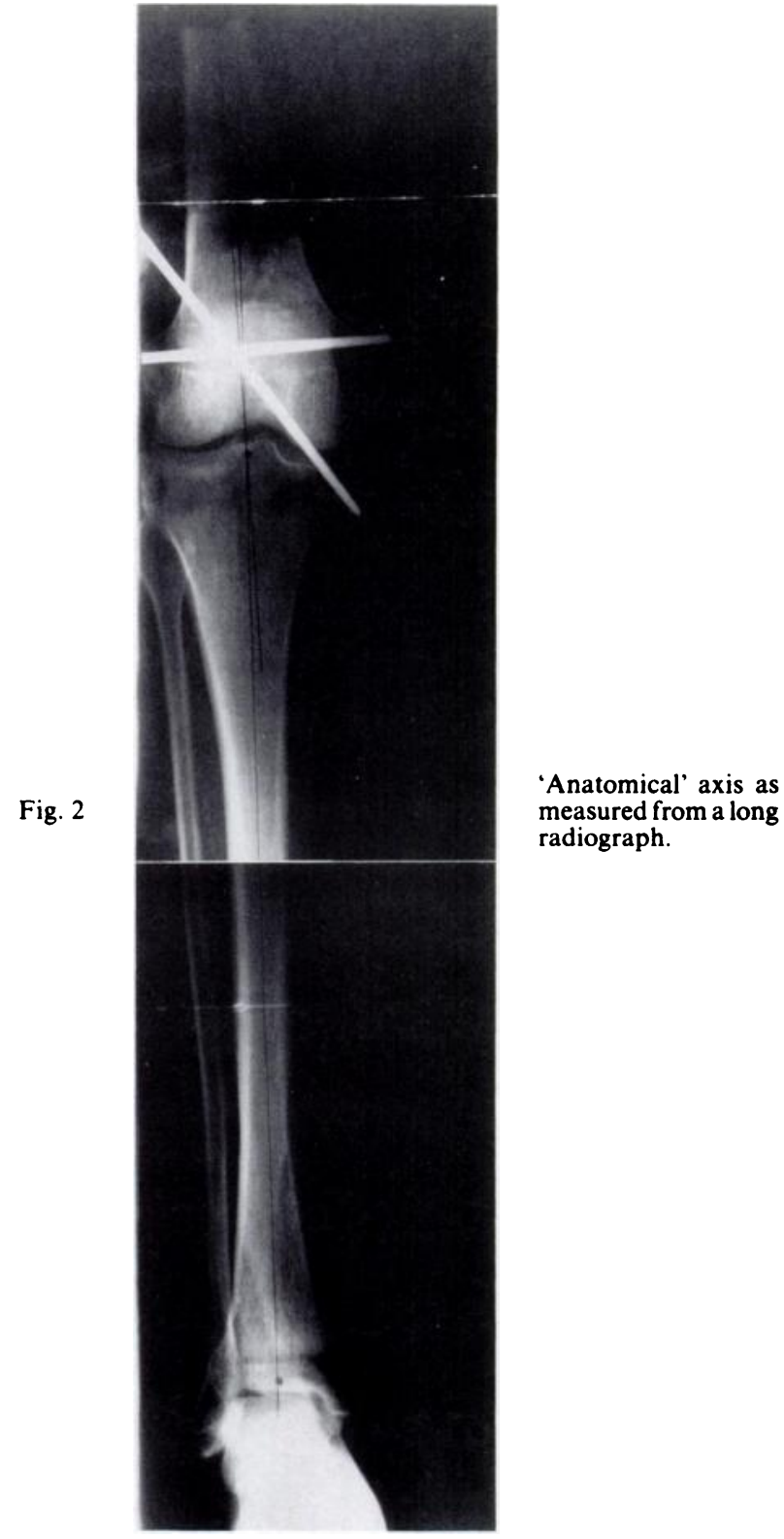

Table I. Effect of rotation and knee flexion on the apparent limb alignment (129 observations)

\begin{tabular}{|c|c|c|c|c|c|c|c|}
\hline \multirow[b]{2}{*}{ Limb } & \multirow[b]{2}{*}{$\begin{array}{l}\text { Knee } \\
\text { flexion }\end{array}$} & \multicolumn{5}{|c|}{ Rotation group } & \multirow[b]{2}{*}{ Mean } \\
\hline & & $\begin{array}{l}20^{\circ} \\
\text { external }\end{array}$ & $\begin{array}{l}10^{\circ} \\
\text { external }\end{array}$ & $\begin{array}{l}0^{\circ} \\
\text { neutral }\end{array}$ & $\begin{array}{l}10^{\circ} \\
\text { internal }\end{array}$ & $\begin{array}{l}20^{\circ} \\
\text { internal }\end{array}$ & \\
\hline $\begin{array}{l}\text { A } \\
\text { A } \\
\text { A } \\
\text { B } \\
\text { B }\end{array}$ & $\begin{array}{r}0^{\circ} \\
20^{\circ} \\
30^{\circ} \\
0^{\circ} \\
20^{\circ}\end{array}$ & $\begin{array}{r}2.0 \\
2.0 \\
-0.3 \\
7.0 \\
2.7\end{array}$ & $\begin{array}{l}1.7 \\
2.8 \\
2.0 \\
3.3 \\
3.7\end{array}$ & $\begin{array}{l}2.0 \\
2.0 \\
4.9 \\
1.0 \\
4.6\end{array}$ & $\begin{array}{r}2.3 \\
1.5 \\
6.7 \\
-0.7 \\
4.3\end{array}$ & $\begin{array}{r}2.0 \\
0.7 \\
9.7 \\
-2.0 \\
4.0\end{array}$ & $\begin{array}{l}2.0 \\
1.9 \\
4.7 \\
1.4 \\
4.1\end{array}$ \\
\hline Mean & & 2.7 & 2.7 & 3.0 & 2.9 & 2.9 & 2.9 \\
\hline
\end{tabular}

The variability between the limbs in the different degrees of knee flexion was greater than the variability between the observers. The intraclass correlation coefficient was 0.96 (graded excellent by the standards of Cicchetti and Sparrow 1981 and Fleiss 1986). 
Table II. Limb alignment: radiographs in neutral rotation reviewed by two observers (69 observations)

\begin{tabular}{lcllll}
\hline & \multirow{4}{*}{$\begin{array}{c}\text { Knee } \\
\text { Limb }\end{array}$} & \multicolumn{2}{l}{ Observers } & \\
\cline { 3 - 5 } & flexion & JW1 & NT1 & NT2 & Mean \\
\hline A & $0^{\circ}$ & 2.4 & 1.4 & 2.2 & 2.0 \\
A & $20^{\circ}$ & 3.3 & 1.7 & 1.3 & 2.1 \\
A & $30^{\circ}$ & 5.4 & 4.6 & 4.8 & 4.9 \\
B & $0^{\circ}$ & 0.6 & 1.4 & 1.0 & 1.0 \\
B & $20^{\circ}$ & 4.2 & 5.0 & 4.6 & 4.6 \\
Mean & & 3.2 & 2.9 & 2.9 & 3.0 \\
\hline
\end{tabular}

Table III. Limb alignment radiographs in neutral and in the four rotated positions reviewed by two observers(129 observations)

\begin{tabular}{|c|c|c|c|c|c|}
\hline \multirow[b]{2}{*}{ Limb } & \multirow{2}{*}{$\begin{array}{l}\text { Knee } \\
\text { flexion }\end{array}$} & \multicolumn{3}{|c|}{ Observers } & \multirow[b]{2}{*}{ Mean } \\
\hline & & JW1 & NT1 & NT2 & \\
\hline $\begin{array}{l}\text { A } \\
\text { A } \\
\text { A } \\
\text { B } \\
\text { B }\end{array}$ & $\begin{array}{r}0^{\circ} \\
20^{\circ} \\
30^{\circ} \\
0^{\circ} \\
20^{\circ}\end{array}$ & $\begin{array}{l}1.9 \\
2.0 \\
4.9 \\
1.1 \\
3.3\end{array}$ & $\begin{array}{l}2.0 \\
1.9 \\
4.7 \\
1.9 \\
4.7\end{array}$ & $\begin{array}{l}2.1 \\
1.9 \\
4.7 \\
1.2 \\
4.4\end{array}$ & $\begin{array}{l}2.0 \\
1.9 \\
4.7 \\
1.4 \\
4.1\end{array}$ \\
\hline Mean & & 2.7 & 3.1 & 2.9 & 2.9 \\
\hline
\end{tabular}

An overall intraclass correlation coefficient was also calculated, including the measurements from the films where we deliberately rotated the limb away from the neutral (Table III). The overall intraclass correlation coefficient was 0.84 . The mean inter-observer difference was $1.4^{\circ}\left(\mathrm{SD}=1.1^{\circ}\right)$ and the mean intra-observer difference was $0.7^{\circ}\left(\mathrm{SD}=0.9^{\circ}\right)$. The intraclass correlation coefficients were 0.96 for the intra-observer measurements, and 0.95 for the inter-observer measurements.

\section{DISCUSSION}

Inconsistent positioning is only one of three sources of measurement variability (Feinstein 1985). The first source of inconsistency is the biological variation of the patient; the second is procedure variability, in this case, in rotation when the limb is positioned. Procedure variability is often not quantitated for radiographic measurements, because patients cannot be exposed to repeated radiographs at the same visit (Floyd 1988). The third source of inconsistency is the intra- and inter-observer variability. The intraclass correlation coefficient is a summary statistic which incorporates the contribution of all three sources of variability.

When positioning a limb with a large angular deformity, variation in limb rotation has an effect on the apparent deformity on the radiograph. To evaluate the effect of rotation on the measurement of limb alignment it was important to include some limbs with angular deformities. Because neither of the two available amputated limbs had a large angular deformity, we created experimental heterogeneity by fixing the knee in flexion.

The radiographer was regularly able to place the limbs within $3^{\circ}$ of neutral rotation, a deviation which introduces only a small measurement variability. Inconsistent positioning in our investigation may be somewhat smaller than expected, because all positioning was done by one person. To test the effect of further rotation, we deliberately rotated the limbs into $20^{\circ}$ of either internal or external rotation but observed only a small overall effect on the apparent alignment on the radiograph. We conclude that in the clinical situation most radiographers would be able to place the limb within $10^{\circ}$ of the neutral position.

Conclusions. In planning our experiment we deliberately tried to reproduce the clinical setting by using unrehearsed observers, and by simulating patients with fixed flexion contracture of the knee. The overall error of measurement was insignificant. Despite the necessary shortcoming of using amputated limbs, we conclude that the reliability of lower limb alignment measured from long radiographs is satisfactory, and that elaborate positioning jigs are unnecessary for routine clinical use.

No benefits in any form have been received or will be received from a commercial party related directly or indirectly to the subject of this article.

\section{REFERENCES}

Bartko JJ. The intraclass correlation coefficient as a measure of reliability. Psychol Rep 1966; 19:3-11.

Cicchetti DV, Sparrow SA. Developing criteria for establishing interrater reliability of specific items: applications to assessment of adaptive behaviour. Am J Ment Defic. 1981 ; 86:127-37.

Cooke TDV, Siu D, Fisher B. The use of standardized radiographs to identify the deformities associated with osteoarthritis. In: Noble J, Galasko CSB, eds. Recent developments in orthopaedic surgery. Manchester University Press, 1987:264-73.

Feinstein AR. Clinical epidemiology - the architecture of clinical research. Philadelphia: WB Saunders, 1985.

Fleiss JL. The design and analysis of clinical experiments. New York: Wiley, 1986.

Floyd AS. Is the measurement of angles on radiographs accurate? $J$ Bone Joint Surg [Br] 1988; 70-B:486-7.

Kramer MS, Feinstein AR. Clinical biostatistics. LIV. The biostatistics of concordance. Clin Pharmacol Ther 1981; 29:111-23.

Moreland JR, Bassett LW, Hanker GJ. Radiographic analysis of the axial alignment of the lower extremity. J Bone Joint Surg [Am] 1987 ; 69-A :745-9.

Shrout PE, Fleiss JL. Intraclass correlations: uses in assessing rater reliability. Psychol Bull 1979; 86:420-8.

Wevers HW, Siu D, Cooke TD. A quantitative method of assessing malalignment and joint space loss of the human knee. J Biomed Eng 1982; 4:319-24. 